\title{
El humanismo del existencialismo
}

\author{
BOLÍVAR ECHEVERRÍA \\ Facultad de Filosofía y Letras \\ Universidad Nacional Autónoma de México \\ bolivare@servidor.unam.mx \\ www.bolivare.unam.mx
}

\begin{abstract}
Resumen: En el contexto inmediatamente posterior a la Segunda Guerra Mundial en Europa, el existencialismo debe afirmarse como corriente filosófico-política, y lo hace oficialmente con la conferencia de Jean-Paul Sartre El existencialismo es un humanismo. Para un discurso como el existencialista era entonces importante ser reconocido como "humanista", porque la renovación de la política de izquierda, en la que pretendía participar, estaba a la orden del día y porque era necesario insistir, frente a los totalitarismos que se enfrentaron en esa guerra, que lo humano se juega en el destino de cada individuo, y no en el de las grandes entidades colectivas y sus metas incontrolables. La redefinición del "humanismo" se volvió indispensable. La que propuso Sartre trató de eludir el retorno a la metafísica que se manifestaba en la de Heidegger, el otro gran "filósofo de la existencia".
\end{abstract}

Palabras clave: Heidegger, Marx, modernidad, movimiento del 68

\begin{abstract}
Immediately after the Second World War in Europe, existentialism is compelled to develop as a politico-philosophical movement. Its official opening occurs in Jean-Paul Sartre's lecture Existentialism is a Humanism. At that time, it was of vital importance for a theoretical movement to be accepted as a "humanist" philosophy as it was also urgent the renewal of leftpolitics to fight against the totalitarian positions that took part in the war. The issue to be highlighted was that of the prevalence of human dignity which is not at sake in the destiny of great collective entities and their overwhelming goals, but in the destiny of each and every individual. A re-definition of the meaning of "humanism" was then unavoidable. Sartre's effort in defining humanism thus implies a step forward to that of the other major "philosopher of existence" Heidegger who returns to a metaphysical recourse in his own definition.
\end{abstract}

Key words: Heidegger, Marx, modernity, 68 movement

Anunciada para las 8:30 de la noche del 29 de octubre de 1945, en el Club Maintenant de París, la conferencia de Jean-Paul Sartre, El existencialismo es un humanismo, comenzó una hora más tarde. Los organizadores, que esperaban llenar apenas el recinto, miran llegar a la gente en grandes cantidades y se enfrentan a una situación que los rebasa. Hay un tumulto, gritos, empujones, sillas rotas, mujeres desvanecidas. Sartre debe improvisar ante un público que tiene dificultades para escucharlo. Expone, con las manos en los bolsillos, como si diera una 
conferencia en la universidad. Comienza inseguro, se gana al público poco a poco y termina entre grandes aplausos. Se trata de un acontecimiento crucial en la historia de la cultura francesa: el existencialismo ha nacido oficialmente.

Los "ismos", las modas intelectuales, aunque parecen fenómenos exteriores, ajenos a lo esencial de una doctrina filosófica, pertenecen al momento expositivo de la misma, sin el cual ésta no llega a realizarse plenamente. Los "ismos" intelectuales corresponden históricamente a la época del liberalismo, cuando la "opinión pública" existía o al menos parecía existir como la expresión de los ciudadanos que está en proceso de autoconfigurarse; eran la presencia viva, con todo lo que esto implicaba de malentendidos, deformaciones y empobrecimientos, de las creaciones mentales de los filósofos. El existencialismo fue, sin duda, el "ismo" por excelencia y, además, el último de ellos. Los "ismos" que aparecieron después de él, el estructuralismo, el posmodernismo, etcétera, llegaron cuando a la filosofía se le había privado ya del escenario de la "opinión pública" como lugar para exponerse. Después de París 68, la "opinión pública" fue sustituida, golpe tras golpe, por una instancia de "autoconciencia" social instalada y reproducida directamente por esa entidad omniabarcante a la que Horkheimer y Adorno llamaron la industria cultural de la modernidad capitalista. Los "ismos" postexistencialistas no pudieron así rebasar el alcance de los pasillos universitarios y las columnas de los suplementos culturales.

El movimiento parisino del 68 no fue sólo un acto de apertura; fue también, en gran medida, un acto de clausura: convocó por última vez, en las calles de su ciudad y en torno al prestigio público del discurso racional, a los ciudadanos convencidos de que detentaban una soberanía. Al despedirse del existencialismo intentando superarlo, despedía también a la época del discurso como instancia decisiva en la vida política formal y agotaba y clausuraba de esta manera la importancia de los intelectuales y sus "ismos", y en general del "ismo" como una figura de la opinión pública.

En París, y sobre todo en el París de la segunda posguerra, los intelectuales poseían todavía un carácter protagónico en la vida social y política; no eran las voces exóticas, aisladas y en definitiva insignificantes que resultan ahora en medio de la dictadura de los mass media. La definición ideológica de los ciudadanos, y sobre todo de los que por cualquier razón aparecían en público: políticos, potentados, científicos, empresarios, literatos, actores y artistas de todo tipo, era entonces una exigencia de suma importancia en su realización como tales. El plano del discurso racional, lugar donde se discuten las ideologías, era la ins- 
tancia de arbitraje aceptada y respetada por toda la sociedad. Lo que allí se jugaba era decisivo para el destino colectivo, o al menos parecía serlo. Los grandes intelectuales, los mâitres à penser, se desenvolvían en ese escenario con un aire sacerdotal; eran oídos y respetados por todos.

Para la noche en que tiene lugar el nacimiento formal del existencialismo, el gobierno del estado francés restaurado, después del aniquilamiento del estado alemán nacionalsocialista que lo venció y lo ocupó durante cuatro años, se encuentra en manos de las fuerzas que ofrecieron resistencia a esa ocupación desde posiciones ideológicas encontradas. La Francia liberada parece indecisa entre los seguidores del general De Gaulle, los "demócratas burgueses", por una parte, y los seguidores del Partido Comunista, los "demócratas populares", por otra. El terreno con el que se identifican, el de la ideología o el proyecto político racional, parece ser el campo determinante del que ambos bandos sacan su legitimidad y su poder. Aparecer en él con una propuesta discursiva alternativa, como pretendía hacerlo el existencialismo, era un hecho que estaba fuertemente sobredeterminado por el enfrentamiento que mantenía en tensión a ese campo.

Leída sesenta años después, la conferencia de Sartre muestra un rasgo sorprendente que tiene que ver con la estrategia expositiva desplegada en ella. Es la estrategia propia de una defensa jurídica, de un plaidoyer. Sartre intenta descalificar las acusaciones que caen sobre el existencialismo y que provienen sobre todo, desde un extremo, de defensores de la doctrina católica y, desde el otro, de militantes del Partido Comunista. Son acusaciones de todo tipo que, sin embargo, se resumen todas ellas en una sola: la acusación de antihumanismo. En una encuesta entre intelectuales de todas las tendencias, promovida por la famosa revista Les Lettres françaises en noviembre de ese mismo año, encontramos expresiones como la siguiente, de Pierre Emmanuel: "No quiero hablar del existencialismo. Es infecto. Me parece una enfermedad del espíritu, incurable. ¿Por qué se nos quiere hacer creer que el hombre es un chancro abominable sobre la faz de la naturaleza?" O como esta otra, del agudo filósofo Henri Lefebvre, que se niega a reconocer entonces una posición que pronto hará suya: "El existencialismo es un fenómeno de podredumbre que está completamente en la línea de la descomposición de la cultura burguesa. El humanismo es una reconquista de la salud humana. Decir 'el infierno son los otros' es negar el humanismo." (Contat y Rybalka 1970, p. 128.)

¿Por qué era tan importante defenderse de esa acusación? ¿Por qué el existencialismo tenía que afirmarse como un humanismo? No se debía únicamente al hecho de que la población francesa, recién salida de 
la época del nazismo, del antihumanismo por antonomasia, necesitaba borrar toda huella de colaboracionismo afirmándose como absolutamente contraria a lo nazi, como humanista. Resultaba importante, sobre todo, porque el humanismo era entonces un concepto de valor emblemático.

Se trataba de encontrar una identidad común capaz de rebasar la heterogeneidad de los dos mundos que se consolidaban rápidamente después de la victoria aliada sobre la Alemania nazi, una definición política compartida que permitiera la convivencia o coexistencia pacífica entre ellos, adelantándose a la instalación de la "guerra fría". Y sólo la identidad humanista era capaz de aceptar por igual los dos adjetivos, el de "burgués" y el de "proletario"; de ser lo mismo liberal que socialista. Si Sartre puso tanto empeño en ser reconocido como humanista es porque, a diferencia del otro gran filósofo de la existencia, Martin Heidegger, que venía de una desilusión y un resentimiento con lo político (encarnado en el estado nazi al que había apoyado), él, por el contrario, partía de un descubrimiento de las oportunidades que la lucha contra el nazismo parecían haber abierto para una regeneración revolucionaria de la política. Adoptar la posición humanista era entonces el mejor modo de comenzar a aprovecharlas.

Si se la lee como un texto filosófico, la conferencia El existencialismo es un humanismo deja mucho que desear; es una introducción a la doctrina de su expositor que vulgariza y disminuye la radicalidad de lo que él tiene escrito en obras como Lo imaginario o El ser y la nada. ${ }^{1}$ Atrapada en el problema moral, simplifica exageradamente la complejidad de la relación entre ética y ontología, que es el núcleo de la filosofía de la existencia. Demasiado atenta a la política coyuntural, deja de lado la problematización de los límites de la misma como actualización real de lo político. De todas maneras, allí donde se atiene al guión estrictamente filosófico que había preparado (Cohen-Solal 1985, p. 329-330), especialmente al final de la conferencia, Sartre alcanza a exponer de manera brillante la idea que el "existencialismo" defiende ante todo y que justifica su nombre: "[En lo que corresponde al modo de ser de lo humano,] la esencia está precedida por la existencia”; es decir, lo que

\footnotetext{
${ }^{1} \mathrm{Al}$ leer la transcripción, a Sartre le molesta ante todo la actitud que fue adoptando bajo la presión del público a medida que avanzaba la primera parte de su exposición, esa actitud de quien dice "todas son calumnias, en verdad somos unos chicos buenos" que llevó a Boris Vian a bromear con el título de la conferencia proponiendo que se llamara más bien "El existencialismo es un moralismo". De todas sus obras, es la única de la que Sartre se ha distanciado en gran parte. (Contat y Rybalka 1970, p. 132).
}

Diánoia, vol. LI, no. 57 (noviembre 2006). 
el ser humano es en cada caso, su consistencia fáctica, sólo se sostiene en la asunción libre que él hace de ella. El ser humano y el mundo de lo humano trascienden la necesidad que los determina como lo que deben ser en cada caso; el ser humano es libre y en su mundo se lee que es fruto de la libertad. Ser libre significa ser capaz de fundar, a partir de la anulación de una necesidad establecida, una "necesidad" diferente, de otro orden; una "necesidad" propia que es ella misma "innecesaria", gratuita, contingente, basada en la nada, sin encargo físico ni misión metafísica alguna que cumplir. ${ }^{2}$

El ser humano sólo existe en la medida en que se inventa a sí mismo. $\mathrm{Al}$ adoptar con sus decisiones una consistencia tal o cual, cada quien se asume ante todo como reivindicador o como represor de lo humano, como libre o como autómata; al elegir entre distintas posibilidades, está "condenado" a elegirse primero como una realización de la libertad o como una renuncia a ella. Hay una "voluntad de libertad", dice Sartre, "que está implícita en la libertad misma". Por ello, por ejemplo, es imposible "elegirse libremente como traidor". La traición es un atentado contra un compromiso entre seres libres, una agresión a la libertad en cuanto tal. El ser traidor implica una claudicación o una destrucción "previa" de la libertad; para "elegirse" como traidor es necesario, ante todo, despojarse de la libertad, suicidarse, dejarse ser el autómataanimal, para el que nada puede ser más valioso que lo que manda el instinto de supervivencia, ejecutar el "designio superior", divino o humano, de anular la libertad propia del compromiso o del juramento con el acto mismo de romperlo.

El humanismo fue originalmente una actitud generalizada entre las elites del nuevo tipo de ser humano que emergía de la obsolescencia de la cristiandad medieval en las ciudades mercantiles y capitalistas del siglo XV europeo. Era una actitud que, sin ser la única, fue la que más caracterizó el intento de este "hombre nuevo" de recomponer lo que la historia de su humanidad cristiana tradicional había anulado

${ }^{2}$ En su Discurso sobre la dignidad del hombre, Pico de la Mirándola escribe:

La limitada naturaleza de los astros se halla contenida dentro de las leyes prescritas por mí. Tú, Adán, determinarás tu naturaleza sin verte constreñido por ninguna barrera, según tu arbitrio, a cuya potestad te he entregado... No te he hecho ni celestial ni terreno, ni mortal ni inmortal, para que por ti mismo, como libre y soberano artífice, te plasmes y te esculpas de la forma que elijas... (2003, p. 21)

Como decían los jesuitas molinistas del siglo XVII, y junto con ellos sor Juana Inés de la Cruz: la mayor "fineza" que Dios puede tener con el ser humano es la de dejarlo en paz, abandonado a su libre arbitrio. 
sistemáticamente; esto es, la riqueza cualitativa concreta de la vida y el mundo de la vida (el "mundo terrenal"), un intento que debía pasar por la reinvención de una identidad concreta para su nueva humanidad poscristiana. ¿De donde podían sacar esas elites un modelo que guiara esa recomposición y esa invención, si no de aquella identidad humana de perfección legendaria, de esa humanitas antigua que había existido antes de la época cristiana y que bien podía tener un "renacimiento"? De la humanitas grecorromana, la actitud humanista de los burgueses del quattrocento se sentía atraída sobre todo por su antropocentrismo: el tipo antiguo de ser humano sobrentendía que el ser humano, y no algún otro ser superior, es "la medida de todas las cosas". En su dimensión sobrehumana, los dioses antiguos, inmortales y poderosos, parecían, sin embargo, no existir para sí mismos, sino para los humanos; se mostraban más fascinados por las peripecias de los mortales que por las suyas propias. Esta concentración de la importancia ontológica en el ser humano, a partir del cual ella se extiende sobre los otros seres, era lo que más atraía al "hombre nuevo" en la imagen que se hacía del cosmos anterior al cristianismo. ${ }^{3}$ Dentro de esta imagen del cosmos antiguo que el humanismo burgués anhelaba reproducir, el "hombre emprendedor", el que desde entonces cree que cabalga sobre el capital y no que es cabalgado por él, se veía retratado en su función de centro del mundo y motor de la dinámica de la historia.

Hipostasiada como "el Hombre" o "la Humanidad", como el sujeto o el fundamento por excelencia, frente al cual todo lo demás es puro objeto inerte o pura "Naturaleza", la actividad libre del ser humano, aquella que se había mostrado en su pureza en el siglo XV, como resultado de la implosión de la cristiandad medieval, y de la que con tanto brillo y tanta esperanza hablaron los filósofos del humanismo renacentista (Pico de la Mirándola: "Tú determinarás tu naturaleza -le dice Dios a Adán - sin verte constreñido por ninguna barrera, según tu arbitrio, a cuya potestad te he entregado..."), fue convertida poco a poco, con la autodefinición capitalista de la modernidad, en objeto de una "antropolatría" que la volvía contraproducente, que la llevaba a esclavizarse a sí misma. El humanismo propio de la modernidad capitalista ha endiosado al Hombre o la Humanidad una vez que le ha adjudicado la omnipotencia que el ser humano enajenado, es decir, el valor de la mercancía capitalista, demuestra tener en un mundo de la vida que sólo parece poder existir como "mundo de las mercancías". El

${ }^{3}$ El humanismo, dice Heidegger (1957, p. 86), "indica aquella interpretación filosófica del ser humano que explica y valora la totalidad de los seres a partir del ser humano y en dirección a él".

Diánoia, vol. LI, no. 57 (noviembre 2006). 
humanismo consagrado por los estados y las instituciones modernas ha puesto al ser humano a adorarse a sí mismo, mejor dicho, a una versión o una metamorfosis suya en la que él está, sin duda, pero enajenado de su propia sujetidad, presente como sujeto-capital; es decir, en la que está activo, pero al mismo tiempo carente de libertad, confundido con el poder de lo otro, lo no-humano, obediente a una voluntad suya que se ha convertido en una necesidad de vigencia metafísica.

Crítico implacable y muchas veces acerbo - como en Jean Genet, comédiant et martyr, uno de sus libros más brillantes- de este humanismo moderno, ${ }^{4}$ Sartre intenta volver a las fuentes protomodernas del humanismo, al humanismo primero de Marsilio Ficino, Pico de la Mirándola $\mathrm{y}$ tantos otros. El humanismo de Sartre realza al ser humano entre los demás seres por tres razones. Aparte de la que ya mencionamos, que "[en lo que corresponde al modo de ser de lo humano,] la esencia está precedida por la existencia" —es decir, que lo que importa en un ser humano es el hecho de que ejerce la libertad a la que "está condenado", de que asume o da sentido a las determinaciones que condicionan su vida, y no lo que esas condiciones hacen de él antes o después de ese ejercicio-, Sartre insiste en una segunda razón: el ser humano es "trascendente", es un ser volcado sobre el mundo para transformarlo, esta "condenado" a la actividad, es responsable de que las cosas marchen por una vía o por otra, de que los objetos del mundo de la vida sigan en el estado en que están o pasen a un estado diferente. La tercera razón del carácter especial del ser humano entre los demás seres consiste, para Sartre, en su estar "condenados" al engagement (compromiso), en el hecho de que su presencia entre los otros los altera tan esencialmente como la presencia de ellos lo altera a él, de que su actividad despierta siempre reciprocidades y responde con otras más, y de que, por tanto, es responsable no sólo de sí mismo, sino también de los otros. "Esta conexión de la trascendencia, en el sentido de superación, [...] y de la subjetividad, en el sentido de que el hombre no está encerrado en sí mismo sino siempre presente en el universo humano, es lo que llamamos humanismo existencialista" (Sartre 1970, p. 93).

Las afirmaciones de Sartre sobre el humanismo no pueden separarse de las que sobre el mismo tema expresó Martin Heidegger, su contemporáneo y maestro, en su famosa carta de 1946 a Jean Beaufret, Sobre el humanismo. ${ }^{5}$ En ella, en respuesta a la conferencia de Sartre de 1945, el pensador de Messkirch emprende todo un autoexamen filosófico. To-

4 "El culto de la humanidad termina en un humanismo cerrado sobre sí mismo y, hay que decirlo, en el fascismo" (Sartre 1970, p. 92).

${ }^{5}$ Heidegger 1954. Los textos sobre el humanismo de los dos principales "filóso- 
mando distancia respecto del "existencialismo", Heidegger interpreta allí la prepotencia del hombre respecto de lo otro o frente a la "naturaleza"; la ve como una hybris o desmesura del sujeto humano de Occidente al instaurar la apertura técnica del ser; una hybris que se ha revertido sobre él en el "destino de devastación" de la "técnica moderna desatada", y que sólo podría revertirse si, a través de un "antihumanismo" restaurador de las jerarquías ontológicas (un antihumanismo que después, a partir de Foucault, tendrá tanto éxito en el posmodernismo), se comienza a pensar que, antes que el hombre, está el ser. Escribe Heidegger:

La esencia del hombre se basa en su ek-sistencia. De esta se trata esencialmente, es decir, del ser mismo, en la medida en que el ser hace acontecer al hombre en la verdad como el que ek-siste para el cuidado de la misma. 'Humanismo' significa así, si nos decidimos a conservar la palabra: la esencia del hombre es esencial para la verdad del ser, y de tal modo, que, consecuentemente, no es sólo el hombre en cuanto tal lo que importa. Pensamos así un "humanismo" muy peculiar. La palabra se vuelve un título que es un locus a non lucendo(una expresión impresentable). (1954, p. 94)

Es interesante anotar que Heidegger, al ubicar su pensamiento en "el plano del ser" y diferenciarlo del existencialismo, que "se quedaría" en el "plano del hombre", parece haber dado un paso atrás respecto de sus planteamientos en Ser y tiempo. Debilita subrepticiamente la idea de la Geworfenheit, del délaissement, es decir, de la falta de sustento o la contingencia propios de la condición humana, y reconstruye una necesidad metafísica para esa condición humana, un sustento que provendría de una relación metaeksistencial del ser humano con el ser, con un ser al que este Heidegger tardío tiende a sustancializar e incluso a antropomorfizar y "personalizar", con fuertes aunque imprecisas insinuaciones teológicas. El ser, que de acuerdo a Ser y tiempo, la obra fundadora de la filosofía de la existencia, no se abre a los humanos más que como un "sentido" de sí mismo, un "sentido" que se constituye precisamente con el dasein, es decir, a través o en virtud de la existencia humana; este ser, cuya manifestación para el ser humano no puede consistir en otra cosa que precisamente en el modo humano de ser, en el dasein

fos de la existencia", Heidegger y Sartre, suelen publicarse juntos, y bastante hay en ello de una injusticia editorial: el uno transcribe la improvisación de Sartre en el Club Maintenant y el otro es, en cambio, el de una carta bien meditada, redactada por Heidegger en la calma de su Hütte en la Selva Negra.

Diánoia, vol. LI, no. 57 (noviembre 2006). 
o la existencia humana, comienza a tratarse en la obra de Heidegger posterior al manuscrito Vom Ereignis de 1936, y muy especialmente en su carta a Jean Beaufret, como capaz de manifestarse no sólo en él sino $a$ él, "desde fuera" o desde "al lado" de él. Sustancializado como algo o alguien de orden metaeksistencial y de rasgos innegablemente cercanos a los del Dios cristiano, el ser "habla" con una voz distinta del modo de ser del dasein, que debería ser su única su voz, para que éste, en una peculiar tautología, le escuche.

Las dos tendencias principales de la "filosofía de la existencia" se separan en este punto; el existencialismo de Sartre sigue la vía decididamente atea y antimetafísica, se afirma en el plano del "estado de yecto" o "condición de arrojado" (de la Geworfenheit o délaissement), enfatiza la "carencia de suelo" (Bodenlosigkeit) y la soledad plena de lo humano, negando toda posible "necesidad" detrás de esta contingencia de la libertad humana; el "nuevo pensar" de Heidegger, en cambio, invita de manera difusa o indecisa a considerar la posibilidad de una pertenencia de lo humano a un designio proveniente del ser (o del "esser", Seyn); insinúa que la libertad puede consistir, en última instancia (en el sentido propuesto por Ignacio de Loyola), en un modo de la obediencia.

Nada hay que pueda darse por ganado en la historia de las ideas; en ella, como en el mito de Sísifo, todo tiene que ser pensado cada vez de nuevo. La noción de progreso no tiene cabida en ella; la sabiduría no es acumulativa. Ningún filósofo posterior a Platón fue "mejor" que Platón, porque pudo filosofar encaramado sobre sus hombros. No obstante, puede hablarse de ideas del pasado (o, mejor, de un presente más amplio que engloba lo mismo a ese pasado que a nuestro presente particular) que se refieren de manera ejemplar a ciertos temas percibidos todavía como actuales, ideas que son capaces de enriquecer la reflexión en nuestros días. La idea central del humanismo sartreano es de ésas.

$\mathrm{Si}$ algo hay que pueda caracterizar a la época moderna es, en palabras de Karl Marx, el fenómeno de la enajenación; es decir, de la entrega del ser humano a una "voluntad" extrahumana que parece actuar desde el ámbito de las cosas; una "voluntad" que, según él, resulta de una peculiar "humanización" de las cosas, de una antropomorfización del valor de las mercancías producidas de modo capitalista cuando se apropia de la voluntad del ser humano, encarna en ella y la subordina a su dinámica de autovalorización. El dominio de la modernidad capitalista convierte a todos y cada uno de los individuos singulares que viven de acuerdo con ella, voluntaria o involuntariamente, en "socios" de sus respectivas entidades estatales capitalistas, en cómplices de la 
explotación, tanto de los otros como de sí mismos, y sobre todo de la abdicación de su dignidad humana, de la renuncia a su carácter de sujetos libres, de artífices de su propia vida.

Condenado a una singularización abstracta que lo atomiza y le impide vivir en comunidad, el ser humano moderno experimenta esa condición enajenada bajo la forma de una represión de su individualidad singular concreta. Rescatarse de esta imposibilidad es el horizonte de su acción libre, que coincide y se confunde con el de la resistencia colectiva, social y política, al dominio del modo de producción capitalista y a la enajenación resultante de él. Sartre propuso a la izquierda rescatar una actitud política que, siendo propia de ella, se encontraba reprimida por un comportamiento y una ideología autodenominados "marxistas" que, al pretender representarla, en realidad la anulaban; propuso reconocer que la acción revolucionaria no consiste en el mero cumplimiento de una "necesidad histórica"; que sólo puede ser el resultado de la coincidencia libre, inventiva, con un proyecto público de política revolucionaria, de cada militante en el acto en que, desde su singularidad concreta, trasciende el estado de cosas que lo conmina a ser realista y bajar la cabeza.

La obra de Sartre recuerda al ser humano de esta modernidad que se sobrevive a sí misma que lo político sólo puede realizarse en la política si está actualizado en el nivel profundo de la existencia individual singular; que la política no puede separarse de la moral, del plano de la elección libre de cada uno en medio de la concreción de su vida cotidiana. Según él —se diría-, la acción de anular y trascender la necesidad realista de ser modernos de manera capitalista, la acción de fundar una necesidad propia que trascienda esa necesidad metafísica, que vaya por encima de la vida garantizada por el capital y su organización económico-política, es una acción de resistencia y transformación que no corresponde solamente a un sujeto social y político mayor, que estaría por constituirse, sino también y sobre todo al sujeto menor, singular e íntimo que puede siempre constituirse en cualquier parte. Incluso si la resistencia mayor a la enajenación moderna se muestra ausente, hay siempre la posibilidad de que se regenere y se reconstruya: a partir de la resistencia pequeña.

\section{BIBLIOGRAFÍA}

Cohen-Solal, Annie,1985, Sartre 1905-1980, Gallimard, París.

Contat, M. y M. Rybalka, 1970, Les Écrits de Sartre, Gallimard, París.

Heidegger, Martin, 1957, Holzwege, Klostermann, Fráncfort del Meno.

Diánoia, vol. LI, no. 57 (noviembre 2006). 
Heidegger, Martin, 1954, "Brief über den 'Humanismus'", en Platons Lehre von der Wahrheit, 2a. ed., Francke, Berna, pp. 53-119.

Pico de la Mirándola, Giovanni, 2003, Discurso sobre la dignidad del hombre, Lonseller, Buenos Aires.

Sartre, Jean-Paul, 1970, L'Existentialisme est un humanisme, Nagel, París. [Versión en castellano: El existencialismo es un humanismo, trad. Carmen Llerena del Castillo, EDHASA, Barcelona, 2006.]

Recibido el 21 de febrero de 2006; aceptado el 4 de mayo de 2006. 